\title{
RESULTS IN 39 BILATERAL RIDLEY INTRA-OCULAR IMPLANTS*†
}

\author{
BY \\ WARREN S. REESE \\ Consulting Surgeon, Wills Eye Hospital, Philadelphia, $\mathrm{Pa}$
}

THE purpose of this communication is to demonstrate that the insertion of the Ridley intra-ocular implant is feasible. No informed, experienced ophthalmic surgeon can deny that this new procedure is a great step forward in the treatment of unilateral cataract, nor that it has helped to focus attention on this baffling condition. I decided that if a reasonable percentage of these operations could be shown to be successful bilaterally it would offer substantial proof of the value of the Ridley operation.

In previous papers I have stated that the Ridley operation is more hazardous than the conventional cataract extraction, but also that a successful Ridley operation results in distinctly better ocular rehabilitation than a successful conventional extraction. The hazards of new methods may be considered worthwhile because of the superior results obtained, the so-called calculated risk. In the United States, it has been stated that our results are better than others, and at the symposium on intra-ocular implants at the Barraquer Institute, held in September, 1958, Ridley was kind enough to say that our results were better than his, explaining, quite properly, that this was probably due to his pioneering. In fact, it seems that Ridley's results and ours are about the same; possibly we have had fewer vitreous dislocations, whereas he has had fewer iris prolapses, etc. I mention this simply to show that if two surgeons have done a fairly large series of these operations with reasonably good results, the operation cannot logically be blamed for some of the bad results of which we have heard.

Not only does the selection of cases require experienced judgment, but the operation itself is difficult and the post-operative care most demanding. The Academy of Ophthalmology and Oto-Laryngology early issued a stern warning against the operation, and I publicly agreed with this dictum in the hope that it would deter inexperienced and unskilled men from attempting it. Unfortunately, the warning seemed to have had the opposite effect, so that few outstanding men tried it. Current opinion, though recently much less prejudiced, is still unfavourable. Every new method must be given considerable trial before its efficacy can be determined; indeed, it may be said that modern cataract extraction has evolved during many years of surgical experimentation on the human eye, starting with the work of von Graefe. It

* Read before the VI Pan-American Congress of Ophthalmology on February 2, 1960, at Caracas, Venezuela.

$\uparrow$ Received for publication May 9, 1960. 
seems that in this respect the Ridley operation has not been given a "square deal", and it is hoped that the data here presented may cause it to be regarded favourably. These data have been difficult to collect as the patients came from various parts of the United States, which made follow-up unsatisfactory and reduced the success of this series, as I shall show.

The Ridley operation was carried out bilaterally in 39 patients (Table). In only one of the 78 eyes did we fail to complete the operation; in this case

TABLE के

RESULTS

\begin{tabular}{|c|c|c|c|c|c|c|c|}
\hline \multirow{2}{*}{ Case No. } & \multirow{2}{*}{$\begin{array}{l}\text { Age } \\
\text { (yrs) }\end{array}$} & \multirow{2}{*}{$\begin{array}{l}\text { Date of First } \\
\text { Operation }\end{array}$} & \multirow{2}{*}{ First Eye } & \multicolumn{2}{|c|}{ Corrected Visual Acuity } & \multirow{2}{*}{$\begin{array}{l}\text { Date of } \\
\text { Second } \\
\text { Operation }\end{array}$} & \multirow{2}{*}{$\begin{array}{l}\text { Second } \\
\text { Eye }\end{array}$} \\
\hline & & & & Distance & Near & & \\
\hline 1 & 50 & 23.8 .53 & Right & $20 / 15$ & J1 & 27.1.54 & Left \\
\hline $\begin{array}{l}2 \\
3 \\
4\end{array}$ & $\begin{array}{l}63 \\
52 \\
55\end{array}$ & $\begin{array}{c}19.5 .53 \\
5.3 .54 \\
13.2 .53\end{array}$ & $\begin{array}{l}\text { Right } \\
\text { Left } \\
\text { Left }\end{array}$ & $\begin{array}{l}20 / 20 \\
20 / 30 \text { to } 20 / 50 \\
20 / 20\end{array}$ & $\begin{array}{l}\text { J1 } \\
\text { J1 to } \mathrm{J} 12\end{array}$ & $\begin{array}{c}8.10 .54 \\
15.11 .54 \\
7.1 .55\end{array}$ & $\begin{array}{l}\text { Left } \\
\text { Right } \\
\text { Right }\end{array}$ \\
\hline 5 & 62 & 7.5.53 & Right & $20 / 20$ & J1 & 9.2 .55 & Left \\
\hline $\begin{array}{r}6 \\
7 \\
8 \\
9 \\
10 \\
11 \\
12 \\
13 \\
14 \\
15 \\
16 \\
17 \\
18 \\
19 \\
20 \\
21\end{array}$ & $\begin{array}{l}54 \\
59 \\
45 \\
64 \\
56 \\
40 \\
53 \\
57 \\
52 \\
70 \\
57 \\
62 \\
61 \\
69 \\
51 \\
38\end{array}$ & $\begin{array}{c}3.10 .52 \\
10.11 .54 \\
17.2 .54 \\
20.1 .55 \\
25.1 .54 \\
14.5 .54 \\
17.12 .53 \\
26.10 .53 \\
3.8 .53 \\
9.11 .55 \\
19.2 .55 \\
23.9 .53 \\
6.11 .53 \\
28.9 .55 \\
6.4 .55 \\
22.8 .56\end{array}$ & $\begin{array}{l}\text { Right } \\
\text { Right } \\
\text { Right } \\
\text { Left } \\
\text { Right } \\
\text { Right } \\
\text { Left } \\
\text { Right } \\
\text { Left } \\
\text { Right } \\
\text { Left } \\
\text { Right } \\
\text { Left } \\
\text { Right } \\
\text { Right }\end{array}$ & $\begin{array}{l}20 / 30+5 \\
20 / 20 \text { to L.P. } \\
20 / 15 \\
20 / 20 \\
20 / 30+ \\
20 / 20-2 \\
20 / 30 \\
20 / 15 \\
20 / 20 \\
20 / 20-1 \\
20 / 40 \\
20 / 20-1 \\
20 / 20-1 \\
20 / 15 \\
20 / 20+3 \\
20 / 15\end{array}$ & $\begin{array}{l}\mathrm{J} 1 \\
\mathrm{~J} 1 \\
\mathrm{~J} 1 \\
\mathrm{~J} 1 \\
\mathrm{~J} 1 \\
\mathrm{~J} 1 \\
\mathrm{~J} 2 \\
\mathrm{~J} 1 \\
\mathrm{~J} 1 \\
\mathrm{~J} 1 \\
\mathrm{~J} 1 \\
\mathrm{~J} 1 \\
\mathrm{~J} 3 \\
\mathrm{~J} 1 \\
\mathrm{~J} 1 \\
\mathrm{~J} 1\end{array}$ & $\begin{array}{c}15.2 .55 \\
18.5 .55 \\
15.6 .55 \\
7.12 .55 \\
8.2 .56 \\
18.4 .56 \\
30.4 .56 \\
21.5 .56 \\
13.6 .56 \\
20.6 .56 \\
7.9 .56 \\
10.10 .56 \\
16.11 .56 \\
2.1 .57 \\
4.3 .57 \\
25.4 .57\end{array}$ & $\begin{array}{l}\text { Left } \\
\text { Left } \\
\text { Left } \\
\text { Right } \\
\text { Left } \\
\text { Left } \\
\text { Right } \\
\text { Left } \\
\text { Right } \\
\text { Left } \\
\text { Right } \\
\text { Left } \\
\text { Right } \\
\text { Left } \\
\text { Left }\end{array}$ \\
\hline $\begin{array}{l}22 \\
23 \\
24 \\
25 \\
26 \\
27 \\
28 \\
29 \\
30 \\
31 \\
32 \\
33 \\
34\end{array}$ & $\begin{array}{l}65 \\
61 \\
75 \\
67 \\
57 \\
57 \\
67 \\
57 \\
58 \\
62 \\
40 \\
54 \\
42\end{array}$ & $\begin{array}{c}13.6 .56 \\
28.11 .56 \\
10.12 .55 \\
1.2 .55 \\
14.2 .56 \\
25.4 .52 \\
31.10 .57 \\
30.1 .58 \\
26.9 .56 \\
6.2 .58 \\
17.4 .57 \\
24.10 .54 \\
23.10 .58\end{array}$ & $\begin{array}{l}\text { Left } \\
\text { Left } \\
\text { Left } \\
\text { Right } \\
\text { Right } \\
\text { Left } \\
\text { Right } \\
\text { Left } \\
\text { Left } \\
\text { Right } \\
\text { Right } \\
\text { Left } \\
\text { Right }\end{array}$ & $\begin{array}{l}20 / 20 \\
20 / 20 \\
20 / 20 \\
20 / 30 \\
20 / 20 \\
20 / 15 \\
20 / 15 \\
20 / 15- \\
20 / 20 \\
20 / 20 \\
20 / 70 \\
20 / 20 \\
20 / 20-3\end{array}$ & $\begin{array}{l}\mathbf{J} 1 \\
\mathbf{J 1} \\
\mathbf{J} 1 \\
\mathbf{J} 3 \\
\mathbf{J} 1 \\
\mathbf{J} 1 \\
\mathbf{J} 1 \\
\mathbf{J} 1 \\
\mathbf{J} 1 \\
\mathbf{J} 1 \\
\mathbf{J} 10 \\
\mathbf{J} 1 \\
\mathbf{J} 2\end{array}$ & $\begin{array}{c}20.6 .57 \\
24.10 .57 \\
21.11 .57 \\
5.12 .57 \\
20.3 .58 \\
17.4 .58 \\
17.4 .58 \\
22.5 .58 \\
19.6 .58 \\
28.10 .58 \\
20.11 .58 \\
15.1 .59 \\
2.4 .59\end{array}$ & $\begin{array}{l}\text { Right } \\
\text { Right } \\
\text { Right } \\
\text { Left } \\
\text { Left } \\
\text { Right } \\
\text { Left } \\
\text { Right } \\
\text { Right } \\
\text { Left } \\
\text { Left } \\
\text { Right } \\
\text { Left }\end{array}$ \\
\hline 35 & 50 & 17.10 .57 & Left & $20 / 30+$ & J1 & 21.5 .59 & Right \\
\hline $\begin{array}{l}36 \\
37 \\
38 \\
39\end{array}$ & $\begin{array}{l}45 \\
48 \\
57 \\
69\end{array}$ & $\begin{array}{c}25.7 .57 \\
29.6 .55 \\
27.6 .57 \\
6.2 .58\end{array}$ & $\begin{array}{l}\text { Left } \\
\text { Left } \\
\text { Left } \\
\text { Left }\end{array}$ & $\begin{array}{l}20 / 20 \\
20 / 30-3 \text { to } 20 / 70 \\
20 / 20 \text { to } 20 / 30 \\
20 / 20\end{array}$ & $\begin{array}{l}\mathrm{J} 1 \\
\mathrm{~J} 1 \text { to } \mathrm{J} 12 \\
\mathrm{~J} 3 \\
\mathrm{~J} 1\end{array}$ & $\begin{array}{l}9.7 .59 \\
21.7 .59 \\
11.8 .59 \\
13.8 .59\end{array}$ & $\begin{array}{l}\text { Right } \\
\text { Right } \\
\text { Right } \\
\text { Right }\end{array}$ \\
\hline
\end{tabular}


loss of vitreous compelled us to change to a conventional extraction, and the eye made a good recovery. There was no case of infection. Glaucoma occurred in five eyes (6.41 per cent.). There were five cases of iris prolapse; while all of these were small, and appeared to give no trouble, they did, I believe, induce glaucoma, as this occurred in two out of the five so that a large percentage of the glaucoma in this series may be attributed to surgical error, if iris prolapse can be so construed, rather than to the operation, per se.

IN 39 CASES

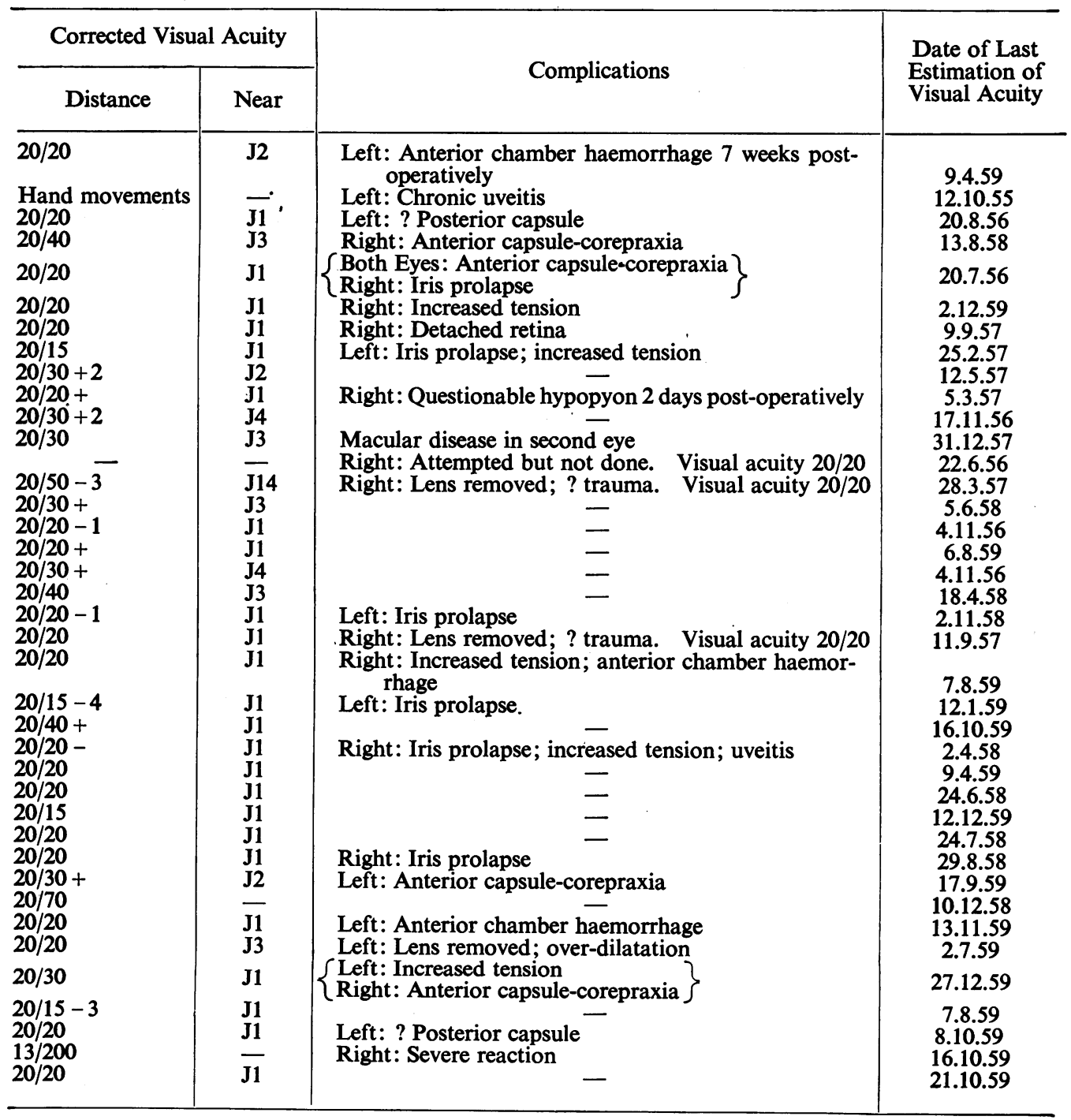


The glaucoma in these cases, I feel sure, responds much better to both medical and surgical treatment than in conventional cases. There was one case of retinal detachment (1.28 per cent.). There were five cases of pupillary occlusion, of which three obtained good vision from a division of the pupillary membrane, which Ridley calls corepraxia. There were no cases of dislocation of the acrylic lens into the vitreous, but in three instances the acrylic lens had to be removed, because of over-dilatation of the pupil from injudicious use of atropine in one case, and trauma in the other two cases. The average corrected distance vision of the eyes with $20 / 200$ or better was $20 / 24$, and the average near vision slightly better than Jaeger 2 . There were four cases in which the vision was less than $20 / 200$. Three had late anterior chamber haemorrhages, but these absorbed and the eyes recovered good vision. Except for striate keratitis, none of these eyes had corneal complications. In one case, neglect of follow-up treatment, due partly to a doctor's prejudice and refusal to see the patient again, resulted in greatly reduced vision from an untreated uveitis. In general, the visual acuity improved remarkably post-operatively over a period of months or even years, and some had exceptionally good uncorrected near and distant vision. In four cases the visual acuity decreased, possibly through the formation of a membrane on the posterior surface of the lens or through malposition of the lens; the cause was not definitely determined, except the case of uveitis mentioned above.

Practically all in this series were private patients who were unusually wellinformed. Indeed, I learned a great deal from some who had read up the ophthalmic literature. Fortunately, they were also very brave and idealistic, and if intra-ocular implants eventually become commonplace, the profession will have these persons to thank. Their attitude imposes a great responsibility on the ophthalmic surgeon, and should deter unskilled and untrained men from simply "trying the operation".

The main obstacle to the more frequent use of this new procedure is the very severe post-operative reaction which is seen in a relatively small percentage of cases. This may even be accompanied by a hypopyon which is very frightening until one finds that it disappears quickly under appropriate treatment. It is possible that improvements in the technique of the operation and in the methods of predetermining, forestalling, or minimizing this reaction may decrease this unfortunate percentage, but this would require time and much more collaboration than has heretofore been possible in the United States, where I have been a lone wolf, especially since the passing of my old friend, Dr. William Zentmayer.

An erisophake-type of instrument is being developed that may not only facilitate the lens implantation and thus reduce post-operative reaction, but may also help to position the lens more accurately, thereby increasing the success of the operation. Ridley recently sent me a new lens which he hopes 
may work better than the present one. When one considers how few surgeons have worked seriously on any large number of cases, it is remarkable how much progress has been made.

This series of 39 bilateral cases has been presented primarily to highlight the various complications and difficulties, since two operations in the same patient disclose more hazards than one. It is my aim to present a simplified and more comparable series than has been hitherto available and to justify my confidence that the Ridley operation can be done successfully. From my own standpoint, the best and simplest way of determining the efficacy of this new method would be to interview and test patients operated on successfully by both methods. 